\title{
Hilda Hilst leitora: UMA INTROdUÇÃo À Biblioteca DA CASA DO SOL
}

Aline Leal Fernandes BARBOSA*

\section{RESUMO}

Tendo em vista a paixão pelo conhecimento e a centralidade da atividade de leitura para a escritora Hilda Hilst - fato identificável na amplitude de sua biblioteca, nas referências a diversos autores em seus livros, nas anotações em seus cadernos e nas entrevistas que dava -, este artigo delineia uma prática de leitura produtiva que acontece simultaneamente a um processo de escrita. Para tanto, faz uma introdução à biblioteca da Casa do Sol, local em que Hilda Hilst viveu por quase quarenta anos e onde construiu a maior parte de sua obra. Ao trazer para a cena os escritos hilstianos que correm à margem do que foi publicado - ampliando, dessa maneira, as materialidades da escrita - questiona-se os fundamentos do que se costuma caracterizar como "obra" literária.

PAlavras-CHAve: Hilda Hilst; arquivo; biblioteca; marginália; processo.

Bolsista do Programa Nacional de Pós-Doutorado da Capes no programa de Literatura, Cultura e Contemporaneidade do departamento de Letras da Pontifícia Universidade Católica do Rio de Janeiro/ PUC-Rio, Rio de Janeiro, Rio de Janeiro, Brasil.

E-mail: alinelfbarbosa@gmail.com. ORCID iD: https://orcid.org/0000-0001-5488-0654 


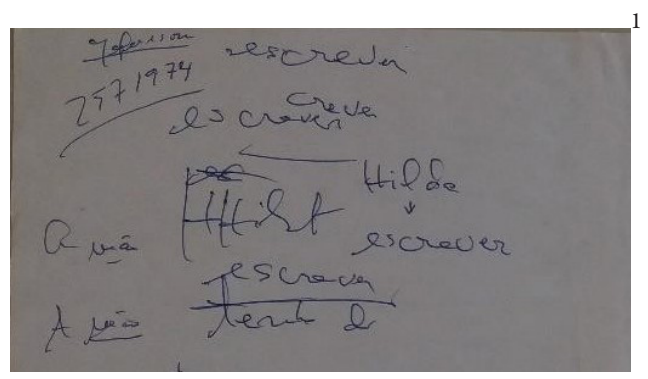

Hilda Hilst (1930-2004) certa vez despertou de um sonho e se lembrou dele para contá-lo. Ela atravessava uma ponte, espécie de passarela para pedestres, como aquela sobre a Avenida Rebouças, na capital paulista. Pessoas iam e vinham nas duas direções, até que ela resolve parar um sujeito e lhe perguntar: onde fica a universidade? Sem necessidade de ir a um divã para saber dos significados do sonho, ela mesma tratou de oferecer a sua interpretação: o conhecimento, que ela buscara durante toda a sua vida, lhe acompanharia até depois da morte, seria este o seu horizonte, o caminho a ser percorrido até o fim. ${ }^{2}$ A paixão pelo saber, a erudição como via a ser trilhada, o interesse vital pelo grande pensamento da humanidade e a reverência pelos grandes autores foram centrais na vida e na obra de Hilda Hilst.

Quando ela decide afastar-se da vida agitada que levava na cidade de São Paulo e refugiar-se em uma fazenda na propriedade de sua família nos arredores de Campinas, construindo ali uma casa para viver - a Casa do Sol - estava delineando o seu projeto intelectual e literário. Inspirada pela leitura de Carta a El Greco, de Nikos Kazantzakis, em que o autor grego

1 Trecho de um papel avulso encontrado no acervo de Hilda Hilst no Centro de Documentação Alexandre Eulálio do Instituto de Linguagem da Universidade Estadual de Campinas (Cedae/IEL/Unicamp) em que ela redige sucessivas vezes: "Escrever, escrever, tenho que escrever".

2 Este sonho foi relatado por Hilda Hilst à sua amiga Olga Bilenky enquanto moravam juntas na Casa do Sol, que, por sua vez, o relatou a mim durante uma das residências que realizei na Casa entre os anos de 2016 e 2017. Olga Bilenky, atualmente diretora do Instituto Hilda Hilst, é viúva de José Mora Fuentes e mãe de Daniel Fuentes, detentor dos direitos autorais da escritora. No acervo de Hilda Hilst, no IEL da Unicamp, há uma pasta reservada aos sonhos que $\mathrm{HH}$ transcrevia ao acordar. 
defende a necessidade do isolamento para tornar possível o conhecimento do ser, ela constrói ali a sua "torre de capim”", em sarcástica apropriação da torre de marfim dos intelectuais.

Ao longo dos quase quarenta anos em que viveu na Casa do Sol, de 1965 até o fim de sua vida, foi acompanhada de forma intermitente por grupos de escritores, artistas, jornalistas ${ }^{4}$, que contribuíram para construir a atmosfera intelectualmente estimulante da casa. Foi nesse ambiente que Hilda Hilst escreveu cerca de $80 \%$ de sua obra, entre poesia, teatro, prosa e crônica. Após a morte da escritora, em 2004, a casa foi tombada e tornouse a sede do Instituto Hilda Hilst, que mantém um programa de residência para aqueles que desejam pesquisar a obra da autora ou tão somente buscam um lugar estimulante para debruçarem-se sobre suas pesquisas intelectuais ou artísticas, de temáticas diversas.

Durante a pesquisa para a tese de doutoramento, visitei pela primeira vez este espaço, já tão assentado no imaginário dos leitores de Hilda Hilst. Ao todo foram três visitas ${ }^{5}$, entre 2016 e 2017, com temporadas de uma semana. Foi nesse ambiente, atravessado por todo o tipo de matéria hilstiana - entre seu escritório, a ampla cozinha, a sala de estar repleta de memórias, entre os cães que tradicionalmente passeiam pelo jardim da Casa do Sol e a sua famosa figueira - que se delinearam alguns dos eixos mais importantes da minha pesquisa. Também foi este o lugar em que, de maneira ainda não calculada, nasceu a ideia de trabalhar sobre a dimensão leitora de Hilda Hilst.

3 A expressão torre de capim aparece em algumas entrevistas concedidas por Hilda Hilst: "O Thomas Mann dizia uma coisa bonita, ele frisava que 'para algumas pessoas que escrevem a vida é um jardim proibido’. Mais ou menos foi isso que senti quando resolvi vir para a Casa do Sol, exclusivamente para escrever. As pessoas comentavam que era uma atitude elitista. Eu caçoava disso, e arrematava: 'Tô na minha torre de capim então'. Aliás, o físico Mário Schenberg, recentemente falecido, costumava brincar comigo sobre essa torre de capim” (MAFRA, Inês. Hilda Hilst: um coração em segredo. Nicolau, Curitiba, n.51, ano VII, nov./dez. 1993).

4 Hilda Hilst muda-se para a Casa do Sol com o seu então marido Dante Casarini, porém a casa estará sempre repleta de amigos, seja como visitas, seja como residentes. Alguns dos nomes conhecidos que passaram por lá são: Caio Fernando Abreu, Lygia Fagundes Telles, Olga Savary, Leo Gilson Ribeiro, Nelly Novaes Coelho, Maria Bonomi, entre outros.

5 Durante a residência, não há compromissos, atividades ou regras. Fica a cargo do residente aproveitar a estada como lhe aprouver. É possível consultar os livros da biblioteca, descansar nas redes da varanda, brincar com os cachorros da casa, passear no jardim, bater papo na cozinha, sentar-se à mesa embaixo da figueira centenária, famosa por atender a pedidos diversos. 
Ao visitante-pesquisador é dado acesso à biblioteca de cerca de três mil e quinhentos livros, incluindo literatura de todo o tipo, da clássica à popular, da filosofia à poesia, da científica à mística. Folhear esses livros é compartilhar não somente os textos que eles encerram, mas a própria experiência de leitura realizada por Hilda Hilst: grifos, observações, diálogos com o autor e com o texto são encontrados entre as páginas de Freud, Beckett, Baudelaire e Borges, entre tantos outros interlocutores. Além disso, nesse material constam desenhos realizados nos espaços em branco (Figura 1) e, não raro, anotações pessoais que nada tem a ver com o texto em contato e que utilizam o papel somente como superfície disponível para a escrita (Figura 2 e 3). Segundo o Instituto Hilda Hilst (2019), cerca de 2.500 livros - ou seja, 70\% da biblioteca - reúnem intervenções da autora, totalizando uma estimativa de 50 mil marginálias.

Figura 1 - Hilda Hilst desenha na página branca da edição original de MEMÓRIA DE UM DOENTE DOS NERVOS

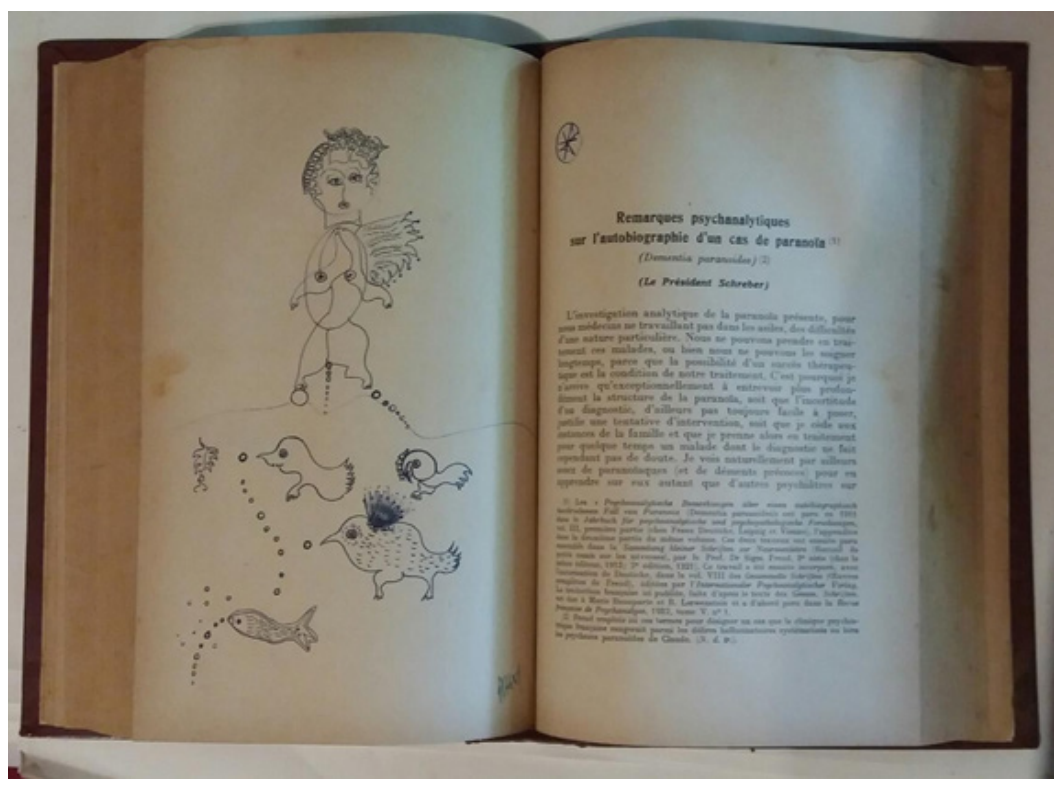

Fonte: Biblioteca da Casa do Sol (2019). 
Figura 2 e 3 - Hilda Hilst faz anotações pessoais nas folhas de rosto e PÁGINAS EM BRANCO
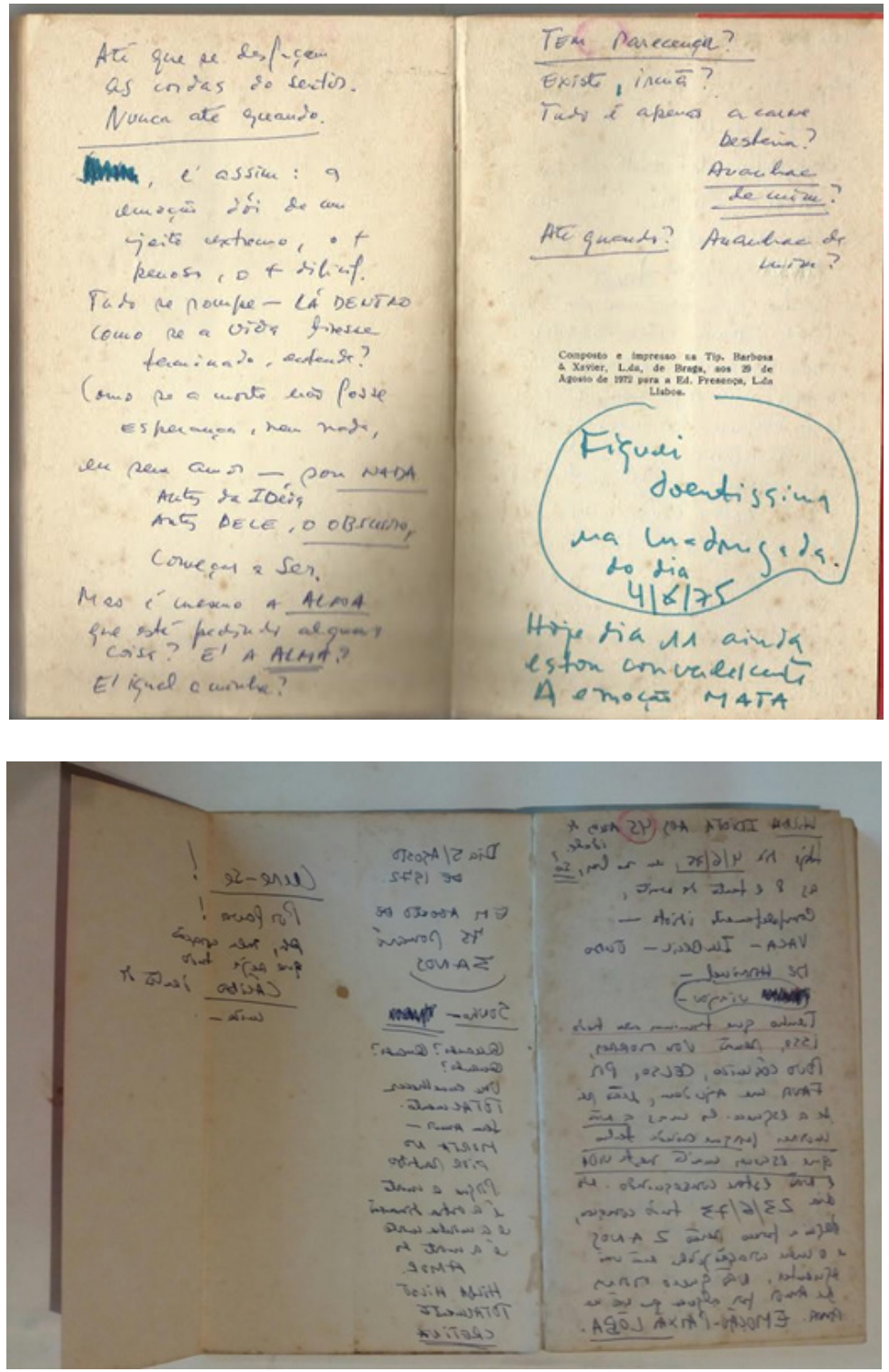

Fonte: Biblioteca da Casa do Sol (2019). 
Embora esforços tenham sido feitos no sentido de catalogar e democratizar o acesso a este acervo, as marginálias permanecem em larga medida inexploradas e carecem de um estudo que realize um levantamento crítico do material, que trace diretrizes de pesquisa e indique possíveis linhas de entrada. A biblioteca de Hilda Hilst forma este novo espaço a percorrer. Uma breve aproximação já possibilita vislumbrar os caminhos da caneta e do pulso, os elos e os projetos inscritos nas marginálias, noções do método de trabalho da escritora, seus dilemas sentimentais e intelectuais que urgem virar palavra escrita em qualquer área livre.

Será justamente este binômio ler/escrever - que Roland Barthes desenvolve em textos como A preparação do romance I e II ([1978] 2005 e 1980 [2005]) e O prazer do texto ([1973] 2015), indicando a leitura como atividade produtiva -, que servirá de condutor para a abordagem da biblioteca hilstiana. Uma leitura carregada de afluxo de ideias, excitações, associações consiste, segundo nossa hipótese, no modo de ler da escritora. Em um pequeno texto chamado Escrever a leitura, Barthes ([1984] 2004) trata de uma dinâmica ao mesmo tempo apaixonada e desrespeitosa de ler levantando a cabeça. Tomado por uma agitação, o leitor se vê solicitado a contorcer-se na cadeira, fazer anotações nos espaços disponíveis, sublinhar algum trecho, interpelar o autor, acrescentar suas próprias ideias às do texto, indicando uma leitura ao mesmo tempo dispersa e fragmentada, intensa e comprometida. Assim, o próprio estatuto de escrita e de leitura estará carregado de corporalidade.

Além disso, segundo Tiscoski (2011), as relações intertextuais entre Hilda Hilst e seus autores de eleição podem ser analisadas por meio do arcabouço teórico de alguns pensadores que estudaram redes de "influência" literária, como Harold Bloom, Julia Kristeva e Gérard Genette, entre outros formuladores das teorias da construção do texto como um "infinito entretecimento", seguindo os rastros de Mikhail Bakhtin, o primeiro pensador da intertextualidade. 
Ao dialogar com uma variedade de textos presentes em sua vida, Hilda Hilst parece estar construindo procedimentos de escrita. A apropriação voraz do alheio a partir de uma prática de leitura intensiva - sempre acompanhada de um escrever - reverbera, ao que tudo indica, em sua própria construção discursiva. Além dos diálogos implícitos ou explícitos com os livros que Hilst realiza em seus textos, a dinâmica de leitura em si parece atravessar sua escrita, imprimindo gestos textuais que tendem ao múltiplo, ao fragmentário, ao dispersivo.

A fragmentação narrativa - procedimento típico da estética hilstiana -, com personagens convocadas a entoar múltiplas vozes, provocam a sensação constante de instabilidade e atordoam o leitor que se aventura a acompanhá-las. Alcir Pécora observa que, por vezes, chega-se a perder os limites que definem essas personagens: "Os 'vários' em Hilda Hilst são mais proliferações inadvertidamente incapazes de se conter numa unidade, do que propriamente essências ou estilos irredutíveis entre si. A verdadeira multidão que ocupa o lugar da narração fala quase sempre com a 'mesma garganta" (PÉCORA, 2003, p. 11). Este órgão é o das personagens-narradoras - que se preocupam com tudo menos com narrar - e que, por vezes, parecem se confundir com a própria escritora.

Pécora (2005) aponta também para a colagem de gêneros em um único texto, indicando uma prática de fusão das formas narrativas a partir da incorporação dos seus limites. Cria-se, assim, uma zona de indeterminação que não somente confunde os princípios hierárquicos entre os gêneros como abala a própria noção de gênero literário. Sobre $A$ obscena senhora D, o autor declara:

Encontram-se lá trechos de poesia lírica (seja pela inclusão de versos na narrativa, seja pela adoção de uma prosa ritmada), de diálogo teatral, com sucessão de réplicas (fazendo com que até o chamado fluxo de consciência tome forma dialógica) e mesmo de crônica (ao comentar acontecimentos ou personagens históricas conhecidas). (PÉCORA, 2005, p.11). 
Hilst transitou entre a poesia, o teatro, a prosa, as crônicas, escrevendo na fronteira entre tais gêneros e se valendo deste cruzamento parar criar sua própria dicção. Pécora tratou de chamar tal procedimento de "anarquia de gênero". Moraes (2008), por sua vez, aplica o termo "prosa degenerada" ao afirmar que Hilst "perverte as leis literárias, criando uma prosa em que os gêneros se degeneram” (p.14).

Assim, ao que tudo indica, a prática de leitura de Hilda Hilst reverberou em seus textos não somente em citações e referências, ou como afirmação ou recusa do estilo de determinado autor; trata-se, porém, de pensar em que medida a própria "indisciplina” narrativa dos textos hilstianos é tributária de uma maneira de ler/ escrever.

\section{CitaÇõES E REFERÊNCIAS}

Conta-se que era frequente que um livro que tivesse interessado Hilda Hilst fosse distribuído para os demais residentes e visitantes da casa a fim de que pudessem debater as ideias e as reflexões que a obra suscitava. ${ }^{6}$ Alguns desses textos foram seminais em sua trajetória, e ela não cansou de citá-los em seus livros e nas entrevistas em que se apresentava com maestria, contribuindo para a construção de uma imagem ousada e desconcertante, e para a criação de mais um gênero hilstiano, além da poesia, da prosa, do teatro e das crônicas. Entre as principais referências, encontramos: Henry Miller, Franz Kafka, Nikos Kazantzakis, Ernest Becker, Liev Tolstoi, Albert Einstein, Sigmund Freud, Jean Paul Sartre, Søren Kieerkegard, entre tantos outros. ${ }^{7}$

6 Olga Bilenky conta que o livro que mais circulou nesse sentido foi A morte de Ivan Ilitch, de Liev Tolstoi, obra que Hilst cita em várias de suas narrativas.

7 Fluente na leitura do inglês, francês e espanhol, encontramos, em sua biblioteca, algumas edições originais. Há uma relação dos livros da biblioteca hilstiana realizada por ocasião da inauguração da sala de memória, um projeto do Itaú Rumos 2015. Seria interessante realizar um estudo crítico sobre esse relatório, pensando em eixos como: autores mais recorrentes, edições originais, edições raras, data das edições etc. 
Ler foi uma atividade prioritária e permanente na vida de Hilda Hilst. Em sua obra, influências de leituras e referências culturais são evidenciadas, as personagens, as epígrafes, as dedicatórias indicando obras e autores que faziam parte de sua formação intelectual. Na trilogia erótica ${ }^{8}$, em que se poderia imaginar que este tipo de abordagem fosse deixado de lado para se privilegiar temáticas menos elaboradas, são inúmeras as citações de livros, filmes, artistas, apontando para as referências pessoais da autora e sua presença marcante na própria obra.

Na entrevista Potlacht, a maldição de Hilda Hilst, que a autora conferiu ao crítico literário José Castello, em 1994, ela tenta explicar o porquê do seu ostracismo, e atribui ao excesso de pensamento em sua obra a causa de seu insucesso entre os leitores: “Todos os meus personagens têm o mau hábito de pensar. Mesmo quando decidi escrever literatura pornográfica, meus personagens viviam com a cabeça cheia de pensamentos. Eles pensam sem parar. Até no meio do sexo decidem fazer perguntas supercomplicadas" (CASTELLO, $1994^{9}$ apud DINIZ, 2013, p.160). Nos dois últimos livros da trilogia erótica são fartas as citações à "alta cultura".

Em Contos de Escárnrio, Textos Grotescos: Vladimir Horowitz, Lucrécio, Ezra Pound, Shakespeare, Grieg, Tchaikovsky, Bach, Spinoza, Kierkegaard, Keats, Yeats, Dante, D.H. Lawrence, Catulo, Freud, Polanski, Fernando Pessoa, Dostoievsky, Betrand Russel, Byron, Shelley, Guimarães Rosa, Euclides da Cunha, entre outros. Em Cartas de um sedutor: Emil Michel Cioran, Liev Tolstói, Søren Kierkegaard, Michel Foucault, Paul Verlaine, Arthur Rimbaud, Jean Genet, George Bataille, Roberto Piva, João Silvério Trevisan, Otto Rank, Daniel Schreber, Arthur Koestler,

8 A trilogia mais tarde consolida-se como tetralogia, com a incorporação do livro de poemas Bufólicas (1992). No entanto, tendo em vista que o projeto original de Hilda Hilst consistia em uma trilogia, vamos tratá-la nestes termos, dando ênfase aos três primeiros livros: $O$ caderno Rosa de Lori Lamby (1990), Contos d'escárnio, textos grotescos (1990) e Cartas de um sedutor (1991).

9 CASTELlO, José. Potlatch, a maldição de Hilda Hilst. O Estado de São Paulo, São Paulo, 30 out.1994. Especial de Domingo, Literatura. 
Nietzsche, D. H. Lawrence, Yukio Mishima, Marcel Proust, James Joyce, Richard Francis Burton, Albert Camus, Freud, Jung, Ovídio, entre outros.

As relações intertextuais aparecem de forma fragmentária, entrando no fluxo de consciência, no fluxo dialógico, na fatura palimpséstica do texto. Além disso, se a listagem apresentada soa como um verdadeiro "name dropping" de referências, é assim como geralmente aparece na própria obra de Hilda Hilst, com personagens que destilam erudição sem se darem ao trabalho de elaborar o pensamento de tais fontes, inserindo-os de forma recorrente em meio a atos profanatórios, realizando um intercâmbio entre as esferas do erudito e do popular.

Convém observar que tal ambiguidade livrou os textos hilstianos - ao serem lidos na chave do indecidível, do inapreensível, por vezes até do intragável - de uma apreensão da crítica canônica de sua época e mesmo do consumo de um número expressivo de leitores. Embora hoje Hilda Hilst seja um nome em ascensão no mercado literário e midiático, a retomada de sua linguagem radicalmente violenta e profanatória interessa menos pelo choque que sua desobediência proposital possa produzir e mais pela potência que se inscreve na escrita. Em Contos d'escárnio, textos grotescos, lemos: "Dona Vivalda quer muito que ele seja, cré, né gente?, um moço de fama, um pianista, o senhor sabe, seu Vlad, que pianista tem que estudar muito, eles têm que tocar Grieg, Tchaikovsky, o Bach o senhor conhece?" (HILST, 2016, p.73). E, em mais uma das inúmeras ocorrências: "Que coisa idiota o sexo, que bela porcaria emerdada isso de comer cu de inglesas ou americanas [...] E eu, que decadência. Eu que na mocidade havia lido Spinoza, Kierkegaard, e amado Keats, Yeats, Dante, alguns tão raros, mas deixem pra lá, enfim que bela droga o que eu vinha fazendo da minha vida" (p. 77). Em seu incansável empreendimento de leitura e estudo, um trabalho que exercia diariamente, Hilst chamava a esses interlocutores de "luminares", apresentando-os como determinantes para a construção de sua obra.

A morte de Ivan Ilitch (1886), obra-prima de Liev Tolstói, verdadeiro tratado sobre a morte, comparece no imaginário de mais de uma personagem hilstiana. Também o protagonista de Cartas de um 
sedutor menciona a novela russa: "Que leituras! Que gente de primeira! O que jogaram de Tolstói e de filosofia não dá para acreditar! Tenho meia dúzia daquela obra-prima A morte de Ivan Ilitch e a obra completa de Kierkegaard" (Hilst, 2013, p.139) ${ }^{10}$. E na entrevista a Caio Fernando Abreu, Hilda Hilst diz: "Existe uma novela que eu acho perfeita: A morte de Ivan Ilitch, de Tolstói. Ele conseguiu chegar ao centro, usando as palavras mais ortodoxas e tal, mas chegou" (DINIZ, 2013, p. 99). ${ }^{11}$

Sabemos também que para Hilda Hilst o livro seminal de Ernest Becker - A negação da morte (1973) - teve uma importância fundamental, e ela não cansou de citá-lo e exaltar a genialidade do escritor em diversas entrevistas ${ }^{12}$. Em um encontro que Nelly Novaes Coelho organizou, uma das críticas literárias contemporâneas à autora que mais prestou atenção em sua obra, Hilda Hilst diz: "Há um homem de que eu gosto muito, que parece ter vindo de uma outra galáxia. Chama-se Ernest Becker. Escreveu um livro chamado A negação da morte, que considero um dos maiores livros escritos nestas décadas." (DINIZ, 2013, p. 114).

São tantos os elogios conferidos a Becker que o leitor de Hilda Hilst fica interessado em conhecer este autor e saber de seu pensamento sobre a morte e o ser humano que vive destinado a esta fatalidade. $\mathrm{Na}$ página de 22 de janeiro de 1979 de uma agenda (Figura 4), Hilst escreve

10 Olga Bilenky, viúva de José Mora Fuentes e residente da Casa do Sol, hoje diretora do Instituto Hilda Hilst, conta que a escritora, fascinada pela novela russa, distribuíra exemplares para diversas pessoas que frequentavam a casa, a fim de que pudessem discutir a obra.

11 Este centro de que se fala aqui remete à resposta anterior de Hilst, que diz: "Fiquei toda a minha vida procurando esse centro, ou uma espécie de tranquilidade - não uma tranquilidade idiota, mas uma certa tolerância com tudo o que te rodeia, com a tua condição de mortal, de apodrecimento" (DINIZ, 2013, p.99).

12 A maior parte das pistas que levam ao livro de Becker foi fornecida pela própria autora, que dedicou grande parte de sua obra ao autor de A negação da morte. Dentre as obras de Hilda dedicadas a Becker estão Poemas malditos, gozosos e devotos (1984), Cantares de perda e predileção (1983), Amavisse (1989), Com meus olhos de cão (1986), Sobre a tua grande face (1986), Da Morte. Odes Mínimas (1980) e A obscena Senhora D (1982), em que consta a seguinte epígrafe: "Dedico este trabalho assim como o anterior, Da morte. Odes mínimas, e também meus trabalhos futuros (se os houver) à memória de Ernest Becker por quem sinto incontida veemente apaixonada admiração". 
sobre o impacto desta leitura: "Releio Ernest Becker. Incrível. Mas se toda essa minha experiência é a dimensão depois da morte, então é preciso pensar tudo de novo. Por que o consciente não registra o espaço-tempo morte como o inconsciente? O inconsciente se pensa imortal? Por quê?” E depois Hilst faz uma pequena lista de "irmãos": Franz Kafka, Ernest Becker, Samuel Beckett, Nikos Kazantzakis, Carl Gustav Jung, Hermann Broch.

Figura 4 - Em página de agenda, Hilda Hilst expressa sua admiração por ERNEST BeCKer.

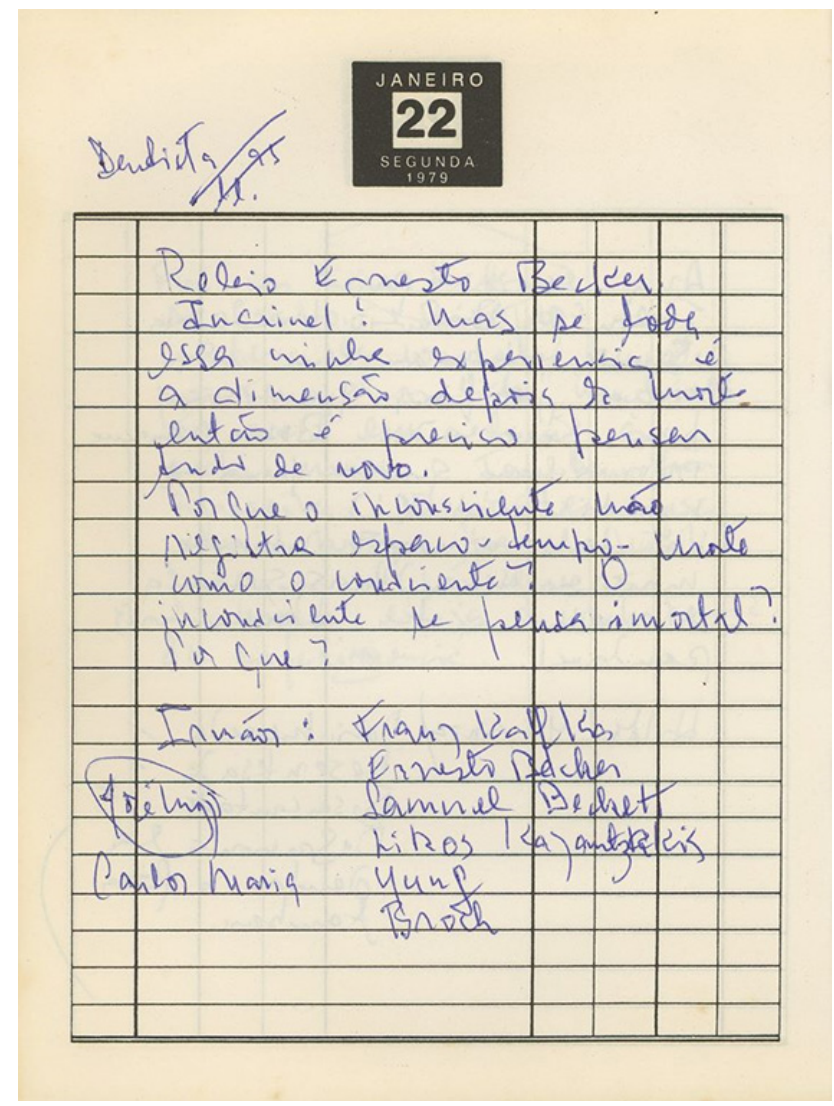

Fonte: Acervo Hilda Hilst, do Centro de documentação Alexandre Eulálio (Cedae - IEL - Unicamp). 


\section{OS LUMINARES}

Foram diversos os autores importantes para Hilda Hilst, porém quatro destacam-se como interlocutores seminais: (1) o grego Nikos Kazantkazis (1883-1957), com o livro Cartas a El Greco, cuja leitura estimulou-a a construir a Casa do Sol, onde realizaria grande parte de sua obra. (2) O norte-americano Henry Miller (1891-1980), cuja concepção do obsceno foi fundamental para a obra hilstiana. (3) O pensador americano Ernest Becker (1924-1974), com A negação da morte, título que Hilst não cansou de citar em seus livros e nas entrevistas que dava, exaltando a genialidade do autor. (4) E o russo Liev Tolstoi (1828-1910), sobretudo com a novela A morte de Ivan Ilitch, citado diversas vezes pelas personagens hilstianas, e cuja leitura causou tamanho assombro em Hilda Hilst que ela distribuía exemplares para os residentes e visitantes da casa a fim de que pudessem debater os temas ali propostos.

Além disso, é possível identificar um percurso de estudos e leituras relacionados ao tema do erótico a partir de registros em seus cadernos e diários e dos livros anotados em sua biblioteca. Autores que trataram do tema do obsceno têm relevância nesta coleção da biblioteca da Casa do Sol, destacando-se entre eles: D.H. Lawrence ( A Barca da Morte, Le Serpent a Plumes - lido em francês - , A Princesa, A Virgem e o Cigano, O Amante de Lady Chatterley, Mulheres Apaixonadas) Henry Miller (A trilogia Sexus, Nexus, Plexus, Pesadelo em Ar-condicionado, Livro de Amigos, Sexteto, Trópico de Câncer), Georges Bataille (Minha Mãe, O Erotismo, O Abade C. , O Azul do Céu, História do Olho, História de Ratos, A Parte Maldita), Marquês de Sade (Ciranda dos Libertinos, Justine ou os infortúnios da virtude, Contos Libertinos), Anais Nin (Delta de Vênus Erótica, Henry, June e Eu, Journal, A Casa só Incesto, Journal 1934-1939, Debaixo de uma Redoma, Pássaros Perdidos, Fome de Amor). Nem todos os livros oferecem a data de leitura, contém marcas de uso ou anotações em suas margens, tornando, portanto, impossível a tarefa de relacioná- 
los com a preparação para escrever a trilogia ou mesmo confirmar a sua leitura. Além disso, na Casa do Sol moraram e frequentaram diversas pessoas ao longo dos quarenta anos em que Hilda Hilst esteve por lá, e na biblioteca - outrora quarto da autora, com suas prateleiras de madeira e hoje um cômodo com um arquivo deslizante de aço - constam diversos livros de Olga Bilenky e José Mora Fuentes, dois dos principais moradores da Casa.

A tessitura dessas diversas camadas - marginálias, cadernos, obra literária, entrevistas -, apontam para a paixão de Hilda Hilst pelo conhecimento e para a sua relação com esses autores: verdadeiros luminares para a escritora, que provocaram seu pensamento e estimularam a produção de sua obra. Essas dobras - leitura, anotação nas margens, elaboração nos cadernos, amadurecimento nas obras e citação em entrevistas - com seus momentos de caos e ordem, de abertura e contorno, apontam para uma escrita da invenção, do cotidiano, do experimental.

\section{CAdERnOS, DiÁRIOS, ILUSTRAÇÕES}

Na década de 1990, Hilda Hilst vendeu grande parte de seu acervo manuscritos, anotações, cadernos, agendas (Figura 5 e 6) - para o Centro de Documentação Cultural Alexandre Eulálio, da Universidade Estadual de Campinas (Unicamp). Ali encontramos um rico material, que vai desde os primeiros exercícios de escrita de uma Hilda em idade escolar, passando por fotografias de várias épocas, relatos de sonhos, correspondências. Um material que chama atenção especial neste acervo são as anotações sobre suas leituras, suas referências filosóficas e literárias, seus interlocutores na paixão pelo saber e pela atividade artística. É interessante encontrar também nesse material reflexões agudas sobre o seu próprio trabalho, talvez para suprir o que ela considerava insuficiência de leitura e crítica. Observa-se aí um dedicado esforço de elaboração de seus temas e de suas personagens, indicando que ela pensava sua obra durante um longo período, e pensava escrevendo. 


\section{Figuras 5 e 6 - Cadernos de Hilda Hilst}
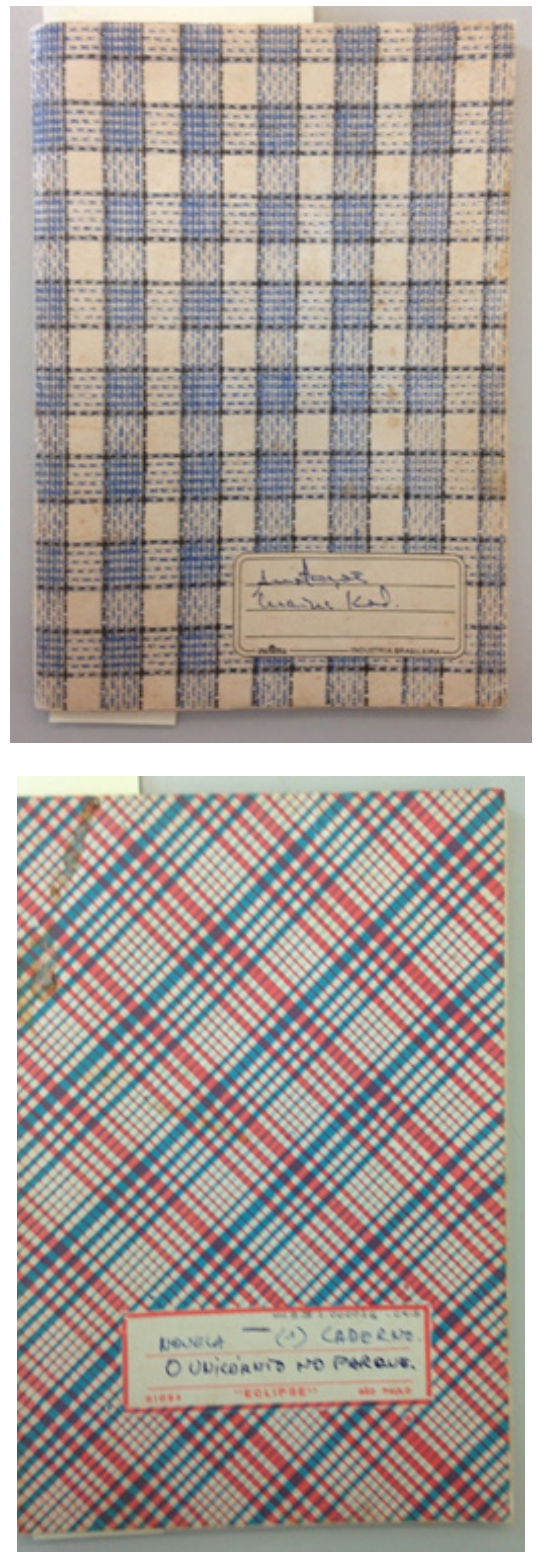

Fonte: Acervo Hilda Hilst, do Centro de documentação Alexandre Eulálio (Cedae/ IEL/ Unicamp). 
Jacques Derrida, em seu livro Mal de arquivo, uma impressão freudiana (2001) traz a categoria de suplemento ${ }^{13}$ para pensar aquilo que, no jogo das substituições, é capaz de deslocar os centros estabelecidos, uma vez que rouba o lugar do significante primordial. O suplemento tem uma qualidade performática na medida em que resiste e substitui aquilo que engloba. Nesse sentido, trata-se de emprestar alguma centralidade (embora móvel e transitória) a esse material que, tradicionalmente, ficou na margem dos estudos hilstianos e, por uma inversão performativa, considerá-los parte fundamental desta obra.

As marginálias, os cadernos, diários - em suma o material considerado paralelo à grande obra autoral, aquela que entra em circulação - têm ganhado destaque contemporaneamente. Valoriza-se o processo na medida do que ele pode revelar sobre a obra e sobre o artista, na medida em que aí se encontram disparadores criativos, além de se delinear e adensar o percurso artístico e a subjetividade daquele que está por trás da obra. Valoriza-se, portanto, não somente a história do sucesso, daquilo que virou obra e circulou, mas também a história do que ficou no meio do caminho, e a interdependência entre essas duas esferas. Assim, traceja-se um percurso íntimo e, ao mesmo tempo, operário, pois ali se revela tanto a personalidade do artista, quanto seu processo de trabalho.

Se, por um lado, algumas anotações das margens dos livros e dos cadernos da escritora revelam a dimensão íntima de sua personalidade, e a produção de sua subjetividade no próprio ato da expressão escrita, ali também encontramos a semente das obras que mais tarde ganharam destaque no circuito literário, apontando para a zona de intercessão entre obra e artista. Ao trazer para a cena os escritos hilstianos que correm à margem do que foi publicado - ampliando, dessa maneira, as materialidades da escrita - questiona-se os fundamentos do que se costuma caracterizar como "obra" literária.

13 Em seu estudo sobre Jean Jacques-Rousseau na Gramatologia, a escrita deixa de ser, para Derrida (1967), um mero elemento compensatório da fala: o suplementar torna-se, assim, uma parte fundamental do que ele suplementa, apontando uma falta essencial, uma espécie de falha no sistema. 
Neste acervo de reflexões fragmentárias, observa-se uma atividade obsessiva de grafar e conservar para o futuro uma reserva de pensamentos a ser deslocada para outras superfícies e sob outros sujeitos da enunciação. Desse modo, tendo em vista os avanços dos estudos hilstianos, indicando a atualidade desta obra, convém ampliar o olhar para este legado e buscar os fios de ligação entre os diversos textos desta linhagem.

The ReAder Hilda Hilst: An Introduction to the Casa do Sol LIBRARY

\section{Abstract}

In view of the passion for knowledge and the centrality of the reading activity for the writer Hilda Hilst - an identifiable fact in the extention of her library, in the references to several authors in her books -, in the notes in her notebooks and in the interviews she gave, this article intends to approach a productive reading practice simultaneously to a writing process. By these means, we will introduce some axis of Casa do Sol library, where Hilda Hilst lived for almost forty years and built most of her work. When bringing to the scene the writings on the margins of what was published, the fundaments usually characterized as literary "work" are questioned.

KEYwORDs: Hilda Hilst; marginalia; library; archive; process.

LA LECTORA Hilda Hilst: una introducción A LA BIBLioteca de LA CASA DO SOL

\section{RESUMEN}

En vista de la pasión por el conocimiento y la centralidad de la actividad de lectura para la escritora Hilda Hilst, un hecho identificable en la amplitud de su biblioteca, en las referencias a varios autores en sus libros, en las notas en sus cuadernos y en las entrevistas que dio, este artículo tiene como objetivo abordar 
la práctica de la lectura productiva que ocurre simultáneamente con un proceso de escritura. Para tanto, realizaremos una introduccion a la biblioteca de Casa do Sol, donde vivió Hilda Hilst durante casi cuarenta años y donde construyó la mayor parte de su trabajo. Al traer a la escena los escritos al margen de lo que se publicó, se cuestionan los fundamentos generalmente caracterizados como "obra” literaria.

Palabras Clave: Hilda Hilst; archivo; biblioteca; marginalia; proceso.

\section{REFERÊNCIAS}

BARTHES, Roland. A preparação do romance I. Organização de Éric Marty e Nathalie Lèger Tradução de Leyla Perrone-Moisés. São Paulo: Martins Fontes, 2005.

. A preparação do romance II. Organização de Éric Marty e Nathalie Lèger Tradução de Leyla Perrone-Moisés. São Paulo: Martins Fontes, 2005. p-26-29.

. Escrever a Leitura. In: O rumor da língua. São Paulo: Brasiliense, 2004. 2015 [1973].

BEATO, Zelina. O conceito de memória e suas implicações para a concepção da tradução como resgate. Revista Tubarão, v. 1, n. 2, p. 157-181, jan./abr. 2014. BECKER, Ernest. A negação da morte. Tradução de Otavio Alves Velho. Rio de Janeiro: Nova Fronteira, 1976.

DERRIDA, Jacques. Mal de Arquivo, uma impressão freudiana. Tradução de Cláudia de Moraes Rego. Rio de Janeiro: Relume Dumará, 2001.

- Gramatologia. Tradução de Miriam Chnaiderman e Renato Janine Ribeiro. São Paulo: Perspectiva, 2013.

DINIZ, Cristiano (Org). Fico besta quando me entendem. São Paulo: Editora, 2013.

HILST, Hilda. Com os meus olhos de cão e outras novelas. São Paulo: Brasiliense, 1986. 
. Cascos \& carícias e outras crônicas. São Paulo: Editora Globo, 2013b.

. Do desejo. São Paulo: Editora Globo, 2014.

. Da morte. Odes mínimas. São Paulo: Editora Globo, 2013.

. Estar sendo, ter sido. São Paulo: Editora Globo, 2013a.

. Fluxo-floema. São Paulo: Editora Globo, 2003b.

. Júbilo, memória, noviciado da paixão. São Paulo: Editora Globo, 2008.

. Pornochic - O caderno rosa de Lori Lamby/Contos d'escárnio textos

grotescos/ Cartas de um sedutor. São Paulo: Editora Globo, 2016.

. Poemas malditos, gozosos e devotos. São Paulo: Editora Globo, 2011.

. Rútilo nada/ A obscena senhora D/ Qadós. Campinas: Pontes, 1993.

. Rútilos. São Paulo: Editora Globo, 2003a.

KAZANTZAKIS, Nikos. Carta a el Greco. Tradução de Clarice Lispector. Rio de Janeiro: Artenova, 1970.

MORAES, Eliane Robert. A prosa degenerada de Hilda Hilst. In: GOMES, Cleusa Gomes; PRZYBYCIEN, Regina. Poetas mulheres que pensaram o século XX. Curitiba: Editora UFPR, 2008.

PÉCORA, Alcir. Hilda Hilst: call for papers. Germina: Revista de Literatura e Arte, ago. 2005. Disponível em: <www.germinaliteratura.com.br/>. Acesso em: 20 jan. 2020. 2003.p. 9-13.

. Nota do organizador. In: HILST, H. Fluxo-floema. São Paulo: Globo,

TISCOSKI, Luciana. Os irmãos de Hilda Hilst: intertextualidade e experiência interior. 2011. Dissertação (Mestrado em Literatura Brasileira) - Universidade Federal de Santa Catarina, Florianópolis, 2011.

TOLSTÓI, Liev. A morte de Ivan Ilitch. Tradução Boris Schneiderman. São Paulo: Editora 34, 2006.

Submetido em 24 de fevereiro de 2020

Aceito em 22 de abril de 2020

Publicado em 31 de maio de 2020 